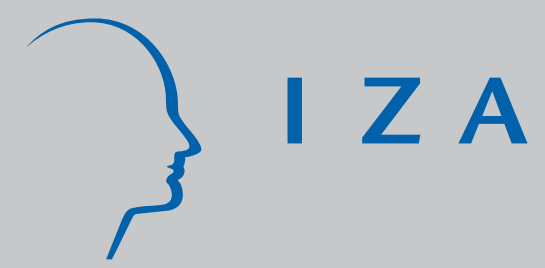

IZA DP No. 6572

Intergenerational Transmission of Neighbourhood Poverty in Sweden: An Innovative Analysis of Individual Neighbourhood Histories

Maarten van Ham

Lina Hedman

David Manley

May 2012
Rory Coulter

John Östh 


\title{
Intergenerational Transmission of Neighbourhood Poverty in Sweden: An Innovative Analysis of Individual Neighbourhood Histories
}

\author{
Maarten van Ham \\ Delft University of Technology and IZA \\ Lina Hedman \\ Uppsala University \\ David Manley \\ University of Bristol \\ Rory Coulter \\ University of St Andrews \\ John Östh \\ Uppsala University
}

Discussion Paper No. 6572

May 2012

IZA

P.O. Box 7240

53072 Bonn

Germany

Phone: +49-228-3894-0

Fax: +49-228-3894-180

E-mail: iza@iza.org

\begin{abstract}
Any opinions expressed here are those of the author(s) and not those of IZA. Research published in this series may include views on policy, but the institute itself takes no institutional policy positions.

The Institute for the Study of Labor (IZA) in Bonn is a local and virtual international research center and a place of communication between science, politics and business. IZA is an independent nonprofit organization supported by Deutsche Post Foundation. The center is associated with the University of Bonn and offers a stimulating research environment through its international network, workshops and conferences, data service, project support, research visits and doctoral program. IZA engages in (i) original and internationally competitive research in all fields of labor economics, (ii) development of policy concepts, and (iii) dissemination of research results and concepts to the interested public.
\end{abstract}

IZA Discussion Papers often represent preliminary work and are circulated to encourage discussion. Citation of such a paper should account for its provisional character. A revised version may be available directly from the author. 


\section{ABSTRACT \\ Intergenerational Transmission of Neighbourhood Poverty in Sweden: An Innovative Analysis of Individual Neighbourhood Histories}

The extent to which socioeconomic (dis)advantage is transmitted between generations is receiving increasing attention from academics and policymakers. However, few studies have investigated whether there is a spatial dimension to this intergenerational transmission of (dis)advantage. Drawing upon the concept of a neighbourhood biography, this study contends that there are links between the places individuals live in with their parents and their subsequent neighbourhood experiences as independent adults. Using individual level register data tracking the whole Swedish population from 1990 to 2008, and bespoke neighbourhoods, this study is the first to use innovative sequencing techniques to construct individual neighbourhood histories. Through visualisation methods and ordered logit models, we demonstrate that the socioeconomic composition of the neighbourhood children lived in before they left the parental home is strongly related to the status of the neighbourhood they live in 5, 12 and 18 years later. Children living with their parents in high poverty concentration neighbourhoods are very likely to end up in similar neighbourhoods much later in life. The parental neighbourhood is also important in predicting the cumulative exposure to poverty concentration neighbourhoods over a long period of early adulthood. Ethnic minorities were found to have the longest cumulative exposure to poverty concentration neighbourhoods. These findings imply that for some groups, disadvantage is both inherited and highly persistent.

JEL Classification: $\quad$ I30, J60, R23

Keywords: intergenerational transmission, neighbourhood poverty, neighbourhood histories, sequence analysis, Sweden

Corresponding author:

Maarten van Ham

OTB Research Institute for the Built Environment

Delft University of Technology

PO Box 5030

2600 GA Delft

The Netherlands

E-mail: m.vanham@tudelft.nl 


\section{Introduction}

There is a large body of literature investigating the intergenerational transmission of (dis)advantage. It has long been recognized that "the fortunes of children are linked to their parents” (Becker \& Tomes, 1979 p.1153; see also Blau \& Duncan, 1967), and it is now well established that individual characteristics, such as labour market earnings and educational attainment, correlate strongly between parents and children. However, there is still a lively debate surrounding the mechanisms producing these patterns and the strength of any causal intergenerational relationships (see for example Dearden et al., 1997; Black et al., 2003). The literature on intergenerational mobility has also been highly bifurcated, with sociologists focusing upon intergenerational mobility across class and occupations, while economists typically analyse income and earnings mobility (for overviews see Solon, 1999; D'Addio, 2007).

The extent to which socioeconomic (dis)advantage is transmitted between generations is also receiving increasing attention from policymakers. In the UK, social mobility has become a key policy issue and one which has implications for the rising inequality that is often identified as a problem in British society (eg. Dorling, 2010). According to the UK government report Opening Doors, Breaking Barriers: A Strategy for Social Mobility "In Britain today, life chances are narrowed for too many by the circumstances of their birth: the home they're born into, the neighbourhood they grow up in or the jobs their parents do. Patterns of inequality are imprinted from one generation to the next” (Nick Clegg, Cabinet Office, 2011). This liberal belief in the importance of severing the links between ascribed or inherited characteristics and individual attainment has become an important policy objective across the developed world, advocated for both equity and efficiency reasons (OECD, 2010).

It has been suggested - sometimes implicitly - that the intergenerational transmission of (dis)advantage also has a spatial dimension (Duncan \& Raudenbush, 2001; Galster \& Killen, 1995; Jencks \& Mayer, 1990; Samson \& Wilson, 1995; Vartanian et al., 2007; van Ham et al., 2012). The idea is that children who grow up in poverty concentration neighbourhoods might be more likely than others to end up in such a neighbourhood as adults. To our knowledge there is only one study to date which empirically investigates this spatial dimension. Vartanian, Buck and Gleason (2007) used sibling data to show for the US that childhood neighbourhood disadvantage has negative effects on adult neighbourhood quality for those living in the lowest quality neighbourhoods.

The possibility of a spatial dimension to intergenerational transmission of (dis)advantage is highly relevant for the literature on neighbourhood effects. This literature investigates whether living in a poverty concentration neighbourhood has a negative effect on residents' life chances (related to, for example, income, education, and health), over and above the effect of their individual characteristics (see for a review Ellen \& Turner, 1997; Galster, 2002; Dietz, 2002; Durlauf, 2004; van Ham \& Manley, 2010; Manley \& van Ham, 2012). Despite an enormous and growing body of literature on neighbourhood effects, there is little agreement on the causal mechanisms which might produce them, their relative importance compared to individual characteristics, and under which circumstances and where these effects are important (van Ham et al., 2012). A major problem in identifying causal neighbourhood effects is that people do not randomly select their neighbourhoods, and as a result parameter estimates for these effects are biased (Durlauf, 2004). People with poor health, low levels of education and who are at risk of unemployment are more likely than more affluent people to 'select' themselves into poverty concentration neighbourhoods where housing costs are low (Cheshire, 2012; van Ham et al., 2013). This process of neighbourhood selection, which over the life course cumulatively creates an individual's neighbourhood biography, may be influenced by the parental neighbourhood. Consequently, individual's life 
outcomes might not only be related to their current neighbourhood, but may also be influenced by their neighbourhood histories.

Insight into the neighbourhood histories of individuals will not only benefit the literature on neighbourhood effects, but will also contribute to our understanding of both segregation and residential mobility processes. Many studies of residential mobility use the life course approach as a starting point and analyse longitudinal data, but few studies investigate true life courses empirically. Most studies investigate transitions in states between two years, for example whether people move from one type of dwelling or neighbourhood to another type between years $t-1$ and $t$ (e.g. Rabe \& Taylor, 2010). As a result, very little is known about the wider neighbourhood biographies within which these events and transitions are situated. This is problematic, as the biographical context within which an event occurs can condition its significance and meaning (Dykstra and van Wissen, 1999; Coulter \& van Ham, 2011). For example, a move from an affluent neighbourhood to a poverty concentration neighbourhood has a very different meaning depending on whether the stay in this poor neighbourhood is temporary or more permanent.

This is the first paper to construct the entire neighbourhood histories of a large group of individuals over a long period of time. We investigated the intergenerational transmission of neighbourhood poverty in Sweden through the effect of the parental neighbourhood on individual neighbourhood biographies over a period of almost two decades. This study hypothesised that the parental neighbourhood has predictive value for neighbourhood outcomes later in live and for the cumulative exposure to poverty concentration neighbourhoods over the life course. To relate the neighbourhood careers of parental home leavers to the last neighbourhood they lived in with their parents, we used 1990-2008 register data from the GeoSweden database. This database contains the whole Swedish population living in the Stockholm area. We defined poverty concentration neighbourhoods based on the percentage of low income neighbours in the local area. We used bespoke neighbourhoods based on the characteristics of the 500 persons living closest to each individual (Östh et al, forthcoming) and used innovative sequencing techniques to visualise individual neighbourhood histories (see Coulter \& van Ham, 2011 for a residential mobility application). Sweden provides an excellent case study for the analysis of the intergenerational transmission of neighbourhood characteristics, as Sweden is widely regarded as one of the least stratified Western societies. As a result, this study provides an important counterweight to the focus on less fluid US and British societies which has characterised the segregation literature.

\section{Literature Review}

To link our understanding of residential mobility (histories) and neighbourhood choice to the literature on intergenerational transmission of (dis)advantage, this study adopts the life course approach as used in many residential mobility studies (Clark \& Huang, 2003). In contrast with the more normative and deterministic life cycle approach, life course theory argues that individuals' experience their own unique sequence of life events as they age (Clark \& Dieleman, 1996; Geist \& McManus, 2008; van Ham, 2012). As a result, individual lives can be thought of as unique personal biographies (Dykstra \& van Wissen, 1999). Mulder and Hooimeijer (1999) argue that the life events occurring within these personal biographies can be grouped into four parallel life course careers. In this framework, it is the sequence of events experienced in these interlinking household, labour force, education and housing careers which influence an individual's residential mobility behaviour throughout their lifetime (Clark \& Davies Withers, 2007). Crucially, the life course model posits that an 
individual's choices and behaviours can be strongly affected by the events or states they have experienced earlier in their life (Dykstra \& van Wissen, 1999; Feijten, 2005; Feijten et al., 2008). Adopting a life course approach therefore guides researchers to analyse the occurrence of events within the long-term individual biography and macro-context within which these are situated (Aisenbrey \& Fasang, 2010).

While the evolution of housing careers across the life course has been a focus for much housing and mobility research (Clark et al., 2003; Feijten \& Mulder, 2005), most studies have been based around the empirical analysis of either cross-sectional data containing some retrospective information, or short periods of longitudinal data (eg. Clark \& Ledwith, 2006; Geist \& McManus, 2008). The result is a focus on year-to-year mobility instead of mobility biographies over the life course. Such studies typically show that households often move between dwellings to adjust their space consumption in response to their changing household needs (Clark \& Dieleman, 1996; Clark \& Huang, 2003). Changes in household composition are also often associated with moves to different types of dwellings in different types of neighbourhoods (Mulder \& Hooimeijer, 1999). In general, younger adults and singles prefer to live in neighbourhoods located closer to jobs and amenities in city centres, while households with children prefer to live in suburban locations (see Kim et al., 2005). Only a few studies of residential mobility and housing careers have focused upon constructing and analysing individual mobility biographies over longer periods of time, using long running panel surveys (eg. Coulter \& van Ham, 2011; Pollock, 2007; Stovel \& Bolan, 2004). These studies have outlined new ways of conceptualising and constructing housing biographies, either as visual timelines (Coulter \& van Ham, 2011) or by using optimal matching methods to identify clusters of similar residential histories (Pollock, 2007; Stovel \& Bolan, 2004).

Given that residential mobility involves neighbourhood as well as dwelling selection, it is surprising that few studies have extended the life course approach to investigate neighbourhood biographies. An increase in socio-economic status over the life course has been found to promote mobility into a more affluent neighbourhood (Rossi, 1980; South \& Crowder, 1997; see also Clark et al., 2003). Vartanian and colleagues (2007) noted that at the same time welfare receipt, public housing (Kasarda, 1988), and homeownership (South \& Crowder, 1997) have been found to be limiting mobility into better neighbourhoods. In general it can therefore be expected that an analysis of neighbourhood biographies will show upward trajectories of neighbourhood status across individual lives. However, there are indications that this might not be equally true for all ethnic groups (Simpson and Finney, 2009). Generally speaking, ethnic minorities live in significantly worse neighbourhoods than ethnic majority groups (Crowder \& South, 2005; Massey et al., 1994; Quillian, 2003) and ethnic minorities are less likely to translate human capital into upward residential mobility (South \& Deane, 1993; Vartanian et al., 2007).

The few studies that have analysed the types of places in which individuals live across their life course have tended to distinguish places according to their population size or physical characteristics rather than their socioeconomic composition. For instance, Stovel and Bolan (2004) distinguish nine 'place-types' ranging from small rural towns to large metropolitan centers. In contrast, Feijten, Hooimeijer and Mulder (2008) classified neighbourhoods according to whether they were located in central city, suburban or rural areas. This study found that the neighbourhood in which an individual grew up in was related to the types of places they lived in later in life (see also Blaauboer, 2011). Feijten and colleagues argue that this may be because children are socialized into preferring a similar type of neighbourhood to that which they grew up in. Similar arguments have been put forward to explain the intergenerational transmission of dwelling preferences (see Helderman \& Mulder, 2007; Kurz, 2004; Mulder \& Smits 1998). Hence, children growing up in an 
owned property are more likely to exhibit preferences for homeownership as adults (Henretta, 1984).

In a spatially segmented housing market, such preferences are also likely to affect neighbourhood choice. As stated in the introduction, to our knowledge there is only one study which explicitly investigated the intergenerational transmission of neighbourhood type (Vartanian et al., 2007). This study used sibling data from the Panel Study of Income Dynamics linked with US Census data. Their results confirmed the hypothesis that childhood neighbourhood disadvantage has negative effects on adult neighbourhood quality for those living in the lowest quality neighbourhoods (Vartanian et al., 2007). They argue that family poverty and the likelihood of residing in disadvantaged neighbourhoods is inherited across generations (c.f. Henretta, 1984). This means that children who grow up in poor neighbourhoods are more likely to reside in similar environments as adults. Vartanian and colleagues explain their findings with neighbourhood effects theory. They suggest that children growing up in poverty areas will experience negative neighbourhood effects on their income and employment opportunities, limiting their subsequent options in the housing market as an independent adult. Furthermore, growing up in a poverty neighbourhood may result in negative effects on their perceptions of their future possibilities of moving to more advantaged neighbourhoods, which may make them even more likely to remain in poverty neighbourhoods as adults.

There are a number of cultural reasons why the type of neighbourhood an individual lived in with their parents may condition their subsequent neighbourhood experiences. A particularly important mechanism for the transmission of neighbourhood quality could be through the inheritance of social norms. Social norms evolve over the life course and are dependent on the type, number and nature of contacts made between people and the environment to which they are exposed. In the parent to child relationship, the greatest impact parents can make on their children's values will be while the child is growing up. Thus, the neighbourhood in which an individual lives as a child could shape their future neighbourhood career. By extension, we can consider whether or not individuals growing up in neighbourhoods that occupy lower positions in the neighbourhood hierarchy are likely to live in similar neighbourhoods later in life, or if they are able to experience neighbourhood hierarchy mobility and move into neighbourhoods with a higher status.

Parents may also socialise their children within certain groups with the (tacit) expectation that they will acquire the cultural traits of these groups. Children will also acquire the norms of their parents as a result of parental actions mediated through their immediate social environment. As they grow up children learn through interaction and observation, potentially adopting the traits that they then enact in later life. This could influence their later behaviour, by altering the types of people they prefer to associate with, the places that they visit and work and, importantly for this paper, the type of places (neighbourhoods) that they wish to live in (see Bisin \& Verdier, 1998). In addition, the intergenerational transmission of earnings, income and educational achievement (Solon, 1999; D’Addio, 2007) is also likely to link the neighbourhood biographies of children and parents. Given the divergent neighbourhood experiences of ethnic groups, ethnicity may be an important factor mediating the intergenerational transmission of neighbourhood (dis)advantage.

Based on the above discussion we expect that the neighbourhood biographies of children leaving the parental home will be related to the parental neighbourhood status. More precisely, we expect that children from poverty concentration neighbourhoods are more likely to sort into poor neighbourhoods as adults than children from more affluent neighbourhoods. We expect the intergenerational transmission of neighbourhood disadvantage to be especially strong for those with parents living in the poorest neighbourhoods. We also expect the transmission effects to be stronger for ethnic minority children than for ethnic majority 
children. Given that cultural and housing market factors may be relevant for transmission processes, we anticipate the effects of parental neighbourhood characteristics to persist even after controlling for the life course attainment of children.

\section{Data and methods}

The data used for this study are derived from GeoSweden, a longitudinal micro-database containing the entire Swedish population tracked from 1990 to 2008. The database is constructed from a number of different annual administrative registers and includes demographic, geographic and socio-economic data for each individual living in Sweden. Within this database, it is possible to follow people over an 18 year period and construct their full neighbourhood histories. In this study we have restricted our selection to people living in the Stockholm metropolitan region ${ }^{1}$. This was to ensure that the definition of 'neighbourhood' was as consistent as possible. It is clear that neighbourhoods in the highly rural far north of Sweden are very different from inner city neighbourhoods, while two neighbourhoods within the Stockholm metropolitan region are more likely to be a similar size. To identify home leavers, we restricted the selection to individuals who were between 16 and 25 years old and living with their parents in 1990 who had left the parental home by 1991. These selections resulted in a total of 13,526 parental home leavers for whom we can construct neighbourhood histories. It is important to note that this is the full population of Stockholm metropolitan region home leavers in 1990-1991, not a sample.

Instead of using standard administrative neighbourhoods we used bespoke neighbourhoods defined using the characteristics of the 500 persons living closest to each individual in the dataset. Using Equipop software (Östh et al, forthcoming) and a dataset with $100 \times 100 \mathrm{~m}$ geo-coordinates ${ }^{2}$ (the smallest geographical coding available in the dataset) the characteristics of the 500 nearest neighbours were calculated for each location for each year (1990-2008). The advantage of this definition compared with using standard administrative neighbourhoods is that the resulting neighbourhood characteristics are a better representation of the actual residential environment of each individual (avoiding boundary effects). For this study on the intergenerational transmission of neighbourhood poverty, the main neighbourhood variable of interest was the share of low income people in the bespoke neighbourhood, where income is defined as personal income from work ${ }^{3}$. Individuals were categorised as having a low income if their income fell into the lowest quintile of the entire Swedish income distribution. Using the Equipop software, we calculated the percentage of low income neighbours among the 500 nearest neighbours of working age for each residential location. The final step was to create quintiles based on this neighbourhood characteristic. Neighbourhoods in the first quintile contain the lowest concentration of low income individuals and neighbourhoods in the fifth quintile contain the highest concentration of low income individuals. Henceforth we refer to these quintile five neighbourhoods as 'poverty concentration neighbourhoods'. Table I gives some basic information on each of the five neighbourhood quintiles for both 1990 and 2008. It can be seen that poverty concentration

\footnotetext{
${ }^{1}$ The Stockholm metropolitan region includes the municipalities of Stockholm and Solna municipalities along with those municipalities of the Stockholm labour market region where the majority of the commuting flow is into either Stockholm or Solna.

${ }^{2}$ The calculations stop when the number of neighbours exceeds 500 . Since the software uses a 100 by 100 meter grid the total number of neighbours included is often slightly higher than 500 .

${ }^{3}$ Income from work is calculated as the sum of: salary payments, income from active businesses, and tax-based benefits that employees accrue as terms of their employment (including sick or parental leave, work-related injury or illness compensation, daily payments for temporary military service, or giving assistance to a disabled relative).
} 
neighbourhoods (quintile 5) have the highest percentage of low income people, the highest share of ethnic minorities and the highest share of public rental dwellings in both years.

\section{$<<<$ Table I about here $>>>$}

The type of neighbourhood where an individual lives can change over time due to residential moves and due to changes in the neighbourhood composition. Because this study focusses on how residential mobility constructs neighbourhood histories, we only allowed the neighbourhood quintile of an individual to change after an actual residential move. Given that neighbourhoods remain relatively constant in the short term (see for instance Meen et al., 2007) this decision will not bias our results. We measure childhood neighbourhood experience by using the last neighbourhood children lived in before they left the parental home. This is largely a pragmatic decision made to enable us to follow people for as long as possible. It has been shown previously that neighbourhood characteristics are highly correlated throughout childhood, so using the last childhood neighbourhood should only produce limited bias (Kuntz et al., 2003; Vartanian et al., 2007).

We then created individual neighbourhood quintile sequences using an innovative visualisation method (for another application see Coulter \& van Ham, 2011). To our knowledge this method has not previously been used to investigate individual neighbourhood histories. Individual sequences were created using SQ-Ados in Stata (version 11). These track the ordering of an element variable over each of the person-years provided by each respondent (Brzinsky-Fay et al., 2006). In this case, the element is the neighbourhood income quintile. The resultant individual neighbourhood histories can be combined and visualised as a series of personal timelines (see Figures 1-3). Within these plots, each horizontal line contains the neighbourhood history of an individual between 1990 and 2008. The timeline is colour coded for each of the years based upon the neighbourhood income quintile experienced in that year. The first segment in each individual history represents the neighbourhood income quintile of the parental address (remember that the study population only includes individuals who left the parental home between 1990 and 1991). All subsequent coloured segments represent the neighbourhoods people lived in after leaving the parental home. If there is no change of colour from one year to the next the individual has not moved, or has relocated but not changed neighbourhood quality. The GeoSweden data is particularly suitable to construct neighbourhood histories as there is almost no attrition (as it is based on register data), and as a result we were able to construct neighbourhood histories for the full population of home leavers in the Stockholm metropolitan region. This would not have been possible using panel data, which often exhibit a high rate of participant attrition in the first years of data collection. This attrition results in a high number of incomplete neighbourhood histories (see also Coulter and van Ham, 2011).

With 13,526 parental home leavers in our research population, the visualisation technique described above would result in a similar number of colour-coded neighbourhood histories. Because of limitations to software, computer screens and printers (limited number of pixels) we had to take a random sample of these histories for display in Figures 1 to 3 (see the figures for details of the random samples used). To be certain that the figures provide a true representation of the full population of home leavers, we reran the analyses several times. The results appeared to be stable (not shown).

Next we modelled the individual neighbourhood histories in two different ways. We first modelled the neighbourhood quintile at $5^{4}, 12$ and 18 years after leaving the parental

\footnotetext{
${ }^{4}$ The reason for modelling outcomes after 5 (in 1995) instead of the more logical 6 years is that data on tenure only is available in 1990, 1995, 2000, 2002, 2004, 2006 and 2008. We have roughly estimated tenure for intervening years.
} 
home. The dependent variable is the neighbourhood quintile based on the percentage of low income neighbours. Because the dependent variable is ordinal, we used ordered logit regression. This model is also known as the proportional odds model because the odds ratio of the event is independent of the relevant category. In ordered logit, a linear function is estimated of the independent variables and a set of cut points, which represent an underlying score (see Feijten \& Mulder, 2005 for a housing related example and van Ham \& Manley, 2009 for an example with neighbourhoods). The coefficients of the independent variables can be interpreted as coefficients estimated in an ordinary logit model. Filling in the full regression equation produces a raw outcome value for each observation in the data. To evaluate the probability that an individual lives in one of the five neighbourhood quintiles it is necessary to calculate a probability for all five categories using the model outcome and the four cut points (identified as K1 to K4) produced by the model. For example, the probability to live in a quintile 1 neighbourhood is:

$$
P=\frac{1}{1+\exp \left(\text { outcome }-K_{1}\right)}
$$

The probability of living in a quintile 2, 3 , or 4 neighbourhood can be calculated using the following equation where $K_{n}$ represents the cut point associated with the category in question:

$$
P=\frac{1}{1+\exp \left(\text { outcome }-K_{n}\right)}-\frac{1}{1+\exp \left(\text { outcome }-K_{n-1}\right)}
$$

The probability of living in a quintile 5 neighbourhood is:

$$
P=1-\frac{1}{1+\exp \left(\text { outcome }-K_{4}\right)}
$$

When combined, the probabilities for all five categories will add up to 1, while the most likely destination neighbourhood will be identified as the one with the highest probability (see Menard, 2002). Finally, we used linear regression to model the number of years an individual home leaver was exposed to quintile 5 neighbourhoods (poverty concentration neighbourhoods) over the 18 year period.

Both the ordered logit models of neighbourhood quintiles after 5, 12 and 18 years and the linear model of cumulative exposure to poverty concentration neighbourhoods include the same set of independent variables (see Table II for an overview). The most important independent variable is the parental neighbourhood quintile in the year before leaving the parental home (1990). Table II shows that in 1995, 5 years after leaving the parental home, the distribution by neighbourhood quintile differs significantly from 1990 when children were still living with their parents. By 1995, the majority of home leavers had moved to higher poverty concentration neighbourhoods (quintiles 4 and especially 5). By 2002 many home leavers had recovered some of the parental neighbourhood status and by 2008 the distribution of neighbourhood poverty status is roughly similar to 1990 again.

Household characteristics are measured by two different variables: whether the individual is single or lives in a registered couple (i.e. is married/registered partner or is cohabiting with a common child) and whether the individual has any children below 18 years of age. Ethnicity is measured using country of birth, separating Swedish born from those born in Western and Non-western countries. In our analyses, we combined the Swedish born and those born in other Western countries and focus especially on the Non-western born, from here on referred to as "ethnic minorities". The socio-economic variables include whether the individual is currently studying, the highest completed level of education (where "medium" refers to a high school degree while a "high" education refers to a university degree), income 
from work (measured in 10,000 SEK) and whether the individual receives social benefits. Finally, we also control for housing tenure.

In the ordered logit models (Table IV) we have measured the independent variables at each of the modelling years: for 1995(5 years after leaving the parental home); for 2002 (after 12 years); and for 2008 (after 18 years). In the cumulative exposure model (Table V) we have recoded some of the variables so that they measure exposure over the 18 year period (for example, the number of years someone has lived in a public rental dwelling over the 18 year period). A set of descriptive statistics of the data use for the years 1990, 1995, 2002 and 2008 can be found in Table II.

$<<<$ Table II about here $>>>$

\section{Results}

Table III shows the cumulative exposure of people to the five neighbourhood poverty quintiles by parental neighbourhood in 1990. The results show that there is a clear relationship between the type of parental neighbourhood and the cumulative exposure to the five neighbourhood quintiles over the subsequent neighbourhood career. Those who lived with their parents in a low poverty concentration neighbourhood (quintile 1) in 1990 are much more likely to spend time in this type of neighbourhood (17.9\% of the next 18 years) then those who lived with their parents in a high poverty concentration neighbourhood (quintile 5) in 1990 (only 9.9\% of the next 18 years. Conversely, those who lived with their parents in high poverty concentration neighbourhoods are much more likely to spend time in such a neighbourhood (48.8\% of the next 18 years) compared to those who lived with their parents in low poverty concentration neighbourhoods (30.6\% of the next 18 years). These results suggest that the parental neighbourhood does indeed have an effect on the neighbourhood biographies of children during their adult life. Those who grew up in a poverty concentration neighbourhood can expect long periods of exposure to this type of neighbourhood in the rest of their lives. According to the neighbourhood effects literature, such exposure to poverty concentration neighbourhoods can have consequences for individual outcomes.

\section{$<<<$ Table III about here $>>>$}

Figures 1.1 to 1.3 show full 18 year neighbourhood histories of parental home leavers, organised by the neighbourhood quintile of the parents' residential address in 1990. Each horizontal line is a unique individual neighbourhood history. A change of colour indicates a move to another neighbourhood quintile. Figure 1.1 shows the neighbourhood histories of those whose parents lived in low poverty concentration neighbourhoods (quintile 1, represented by the colour blue) in 1990. The histories have been ordered based on neighbourhood quintile in 1990, 1991, 1992, etcetera. Therefore all individual neighbourhood histories in this Figure start with a blue line segment. In the first year after leaving the parental home, a large group of home leavers from these relatively affluent neighbourhoods move to a poverty concentration neighbourhood (quintile 5, represented by the colour grey), but the vast majority recover neighbourhood status over the subsequent years. It is striking to see the variety in neighbourhood histories among our research population. Previous studies have only investigated year-to-year transitions between neighbourhood types, and we are able to visualise the full histories in all their complexity. The final column to the right of the Figure shows the same data but sorted by the final destination neighbourhood quintile in 
2008. Here it can be seen that there is a relatively equal distribution across all 5 quintiles, although there seems to be a slight bias towards the higher quintiles. Nevertheless, only a small proportion of those whose parents lived in the first quintile end up in the same quintile 18 years later. Any intergenerational transmission of neighbourhood advantage clearly takes a great deal of time to appear.

\section{$<<<$ Figure 1.1 about here $>>>$}

Figure 1.2 shows the neighbourhood histories of those whose parents lived in quintile 3 neighbourhoods (the middle category, represented by the green colour). Figure 1.2 shows a pattern that is roughly comparable to Figure 1.1, although those starting in quintile 3 are slightly more likely to move to quintile 3 and 4 neighbourhoods immediately after leaving the parental home. It is striking that those who started in quintiles 1 and 3 have very similar outcomes after 18 years (compare the final columns of Figures 1.1 and 1.2). After 18 years there is a roughly equal distribution over the 5 neighbourhood types, regardless of where people started.

Figure 1.3 shows a radically different picture. These are the histories of those whose parents lived in quintile 5 (high poverty concentration) neighbourhoods in 1990 (represented by the colour grey). Table III has already shown that these people are much more likely than others to be exposed to poverty concentration neighbourhoods over their life course. Two thirds of the home leavers with parents in a high poverty concentration neighbourhood move to a similar neighbourhood when they leave the parental home. Over the years, many subsequently move to more affluent neighbourhoods. Nevertheless, the final column in Figure 1.3 shows that after 18 years they are much more likely than others to live in a poverty concentration neighbourhood themselves. It is important to note that the neighbourhood careers of those starting in high poverty concentration neighbourhoods are very diverse. Many histories show episodes in quintile 1 and 2 neighbourhoods (represented by the colours blue and red), but not as many as in Figure 1.1 with the histories of those starting off in low poverty neighbourhoods. Although there is clear evidence of intergenerational transmission of neighbourhood poverty in Figures 1.1 to 1.3, the neighbourhood careers of individuals starting in similar types of neighbourhoods are also highly heterogeneous in the short-term.

\section{$<<<$ Figure $1.2-1.3$ about here $>>>$}

Figure 2 shows the neighbourhood histories of ethnic minority children who lived with their parents in a poverty concentration neighbourhood (quintile 5) in 1990. The difference with the full population (Figure 1.3) is striking. Ethnic minorities are much more likely than the general population (the majority of which are Swedish born) to move into high poverty concentration neighbourhood in the year they leave the parental home. They are also much more likely to spend a considerable amount of time in poverty concentration neighbourhoods during their neighbourhood histories. However, perhaps the most striking difference between Figures 1.3 and 2 is the difference in the final destinations of the ethnic minorities compared with the general population. Individuals from ethnic minorities with parents in a high poverty concentration neighbourhood are much more likely than others (roughly two thirds compared to about one third) to end up in a similar type neighbourhood after 18 years. The figures demonstrate that neighbourhood disadvantage is transmitted particularly strongly between generations of ethnic minority families.

$<<<$ Figure 2a-2b about here $>>>$ 
Figures 1 and 2 contain selections of neighbourhood histories based on the parental neighbourhood in 1990. There are many other ways in which the neighbourhood histories can be ordered and categorised. One such alternative categorisation is based on whether people show downward or upward mobility over the period 1990-2008, or whether they experience a stable history over this timeframe. As an illustration, we show the stable mobility histories in Figure 3. In this Figure all five parental neighbourhood quintiles are represented on the left hand side. Each of the histories starts with the same colour it ends with (the same neighbourhood quintile) and hence we labelled these stable neighbourhood histories. A major advantage of our visualisation method is that it reveals that although the histories are stable in terms of starting and end points, there is a lot of mobility in between. The colour coding clearly shows that the stable quintile 1 histories show many more episodes in quintile 1 and 2 (blue and red) than the other histories. On the other hand, the stable quintile 5 (high poverty concentration neighbourhoods) histories contain many more episodes in quintile 4 and 5 neighbourhoods. These results show great continuity in neighbourhood status over the life course.

\section{Multivariate models}

To understand how neighbourhood histories have developed over time, we modelled neighbourhood outcomes at 5, 12 and 18 years after leaving the parental home using ordered logit regression (Table IV). This enables us to investigate whether the intergenerational transmission of neighbourhood status visible in the Figures remains important after controlling for other attained, inherited or ascribed individual characteristics. Informed by the above visualisations, we have included the parental neighbourhood quintile in 1990 and a dummy variable to indicate ethnicity. To see if the intergenerational transmission of neighbourhood poverty is mediated by ethnicity, we included an interaction effect between ethnicity and parental neighbourhood type. For each of the years we show a model with and without parental income in 1990 because we want to know whether neighbourhood outcomes for children are a result of parental income or parental neighbourhood. Since we know from the literature on the intergenerational transmission of disadvantage that the income of parents and children is related, it is likely that any similarity in neighbourhood is simply a result of income. Although this would be an interesting finding in itself, here we are looking for an independent effect of the parental neighbourhood on the neighbourhood outcomes of children.

The results clearly show that the parental neighbourhood is a strong predictor of neighbourhood (dis)advantage for children 5, 12 and 18 years after leaving the parental home. The higher the poverty concentration of the parental neighbourhood, the higher the poverty concentration of the neighbourhood of their children later in life. It is important to note that this effect holds after controlling for a range on individual and household characteristics, including the parental income. The effect of being a non-Western immigrant on neighbourhood outcomes is more complicated. The main effect for non-western immigrants is not significant in the models unless parental income is also included. The only significant effect can be found in the model with parental income at 5 years after leaving the parental home. Here, non-western immigrants are much more likely to live in a poverty concentration neighbourhood then others. This indicates that non-western immigrants are disadvantaged in the first years after leaving the parental home, but then catch up later in life. The interaction effect between immigrant status and parental neighbourhood is only significant after 12 and 18 years for those with parents in the highest poverty concentration neighbourhoods. However, the effects disappear when controlled for parental income. This 
leads to the broad conclusion that the ethnicity effect found in the visual analysis of neighbourhood histories is caused by income differences between groups.

\section{$<<<$ Table IV about here $>>>$}

The control variables show that there are no significant gender or child effects on neighbourhood outcomes. Those living with a partner are less likely to end up in poverty concentration neighbourhoods than singles. This is most likely due to the higher level of resources available to households with two earners. After 5 years, those with a middle level of education are the least likely to end up in poverty concentration neighbourhoods compared with those with lower and university level education. For those with a university level education, this can be explained by the fact that they start their housing career somewhat later due to investments in their human capital. This is confirmed by the finding that after 18 years those with a university degree are the least likely to end up in a poverty concentration neighbourhood. Greater levels of income from work reduces the probability of ending up in a poverty concentration neighbourhoods, whilst being on social benefits increases the probability. Those living in public rented accommodation are the most likely to end up in poverty concentration neighbourhoods, followed by those in private renting, cooperative housing and owner occupied housing.

The final models in Table $\mathrm{V}$ report the effect of cumulative exposure to high poverty concentration neighbourhoods (quintile 5) over the full 18 year period after leaving the parental home. The maximum exposure time in this model is therefore 18 years. The results clearly demonstrate that individuals who lived with their parents in quintile 4 and especially quintile 5 neighbourhoods in 1990 spend significantly longer in poverty concentration neighbourhoods over the next 18 years than those who grew up in the low poverty concentration neighbourhoods. Non-western immigrants have especially long exposure times to high poverty concentration neighbourhoods, also after controlling for parental income. The interaction effects between immigrant status and parental neighbourhood do not indicate an additional effect for immigrants (which was the case in a model without parental income, effects not shown). The control variables show that having a middle level income reduces the cumulative exposure to poverty concentration neighbourhoods. Having a high mean income, and an increase in income during the 18 years (measured by income range) also reduce cumulative exposure to poverty neighbourhoods. In contrast, receiving social benefits increases exposure to poverty concentration neighbourhoods. With increasing number of years in public renting the exposure to poverty concentration neighbourhoods increases, while spending greater periods of time in homeownership reduces the exposure to the most disadvantaged neighbourhoods.

\section{$<<<$ Table $\mathrm{V}$ about here $>>>$}

\section{Conclusions}

This is the first study to empirically investigate whole neighbourhood histories for 18 years after children leave their parental home. By constructing neighbourhood histories, this paper has sought to empirically operationalize the concept of unique individual biographies emphasised by life course theory. As such, accurately measuring the extent to which parental neighbourhood context is transmitted to children and understanding the factors that lead to neighbourhood sorting by individuals is critical to understanding residential outcomes later in life. There is a vast literature on neighbourhood effects that ties individual outcomes to the 
neighbourhood in which they currently live. By taking a much longer term view we have demonstrated that individual outcomes are influenced over a much longer timescale: where individuals lived up to 18 years ago is important for their current outcomes.

Using innovative visualisation techniques, we have shown that individuals sort themselves into neighbourhoods across the income spectrum as they move through the life course. The graphs clearly showed that although many individuals experienced an initial drop in neighbourhood status immediately after leaving the parental home, many catch up in their subsequent residential career. However, we also demonstrated that those living with their parents in a poverty concentration neighbourhood are significantly more likely to end up in a similar neighbourhood as an adult. These results were confirmed by the multivariate analyses. The results show that the intergenerational transmission of disadvantage is a powerful mechanism explaining the residential outcomes of individuals across their life course. It is important to note that we found these results for Sweden, one of the Nordic countries more commonly associated with equality in outcomes. Based on our results we would expect to find even stronger intergenerational transmission of disadvantage in a country like the UK, which has a more segmented housing market and a more unequal income distribution than Sweden.

The study has also shown that the parental neighbourhood is highly predictive for the cumulative exposure to poverty concentration neighbourhoods over the life course. In particular, ethnicity was found to be a strong predictor of cumulative exposure to poverty neighbourhoods, especially for those with parents in the highest poverty concentration neighbourhoods (although this latter effect could be explained by the parental income). That parental neighbourhood type has such a long-lasting impact on exposure, even after controlling for a variety of changes occurring elsewhere in the life course, suggests that disadvantage is not solely transmitted through education and income, but is also linked to living in poverty neighbourhoods.

The findings of this study have important implications for the literature on neighbourhood effects, as well as our understanding of the role of places across the life course. We have clearly demonstrated that adult exposure to poverty concentration neighbourhoods is linked to the neighbourhood that an individual lived in with their parents. This indicates that neighbourhood effects might run between generations and suggests that not just the current neighbourhood, but the whole neighbourhood history, should be taken into account when investigating whether people are disadvantaged by where they live.

\section{Acknowledgements}

The research reported in this paper was made possible through the financial support of the Institute for Housing and Urban Research (IBF) at Uppsala University, Gävle, Sweden and the financial support of the EU (NBHCHOICE Career Integration Grant under FP7-PEOPLE2011-CIG).

\section{Reference list}

Aisenbrey S and Fasang A E 2010 New life for old ideas: The "second wave" of sequence analysis bringing the "course" back into the life course Sociological Methods \& Research 38 420-462

Becker G S and Tomes N 1979 An Equilibrium Theory of the Distribution of Income and Intergenerational Mobility Journal of Political Economy 87(6) 1153-1189 
Bisin, A and Verdier T 1998 On the cultural transmission of preferences for social status Journal of Public Economics 70(1) 75-97

Blaauboer M 2011 The Impact of Childhood Experiences and Family Members Outside the Household on Residential Environment Choices Urban Studies 48 1635-1650

Black S E Devereux P and Salvanes K G 2005 Why the Apple Doesn't Fall Far: Understanding Intergenerational Transmission of Human Capital American Economic Review 95 (1) 437-449

Blau, P M and Duncan O D 1967 The American Occupational Structure New York, Wiley

Brzinsky-Fay C Kohler U and Luniak M 2006 Sequence analysis with StataTheStata Journal 6 (4) 435-460

Cabinet Office 2011 Opening Doors, Breaking Barriers: A Strategy for Social Mobility London

Cheshire P 2012 Are mixed community policies evidence based? A review of the research on neighbourhood effects In van Ham M Manley D Bailey N Simpson L and Maclennan D edsNeighbourhood Effects Research: New Perspectives Dordrecht, Springer

Clark W A V and Davies Withers S 2007 Family migration and mobility sequences in the united states: Spatial mobility in the context of the life course Demographic Research17 591-622

Clark W A V Deurloo M and Dieleman F M 2003 Housing careers in the United States, 1968-93: Modelling the sequencing of housing states Urban Studies40 143-160

Clark W A V and Dieleman F M 1996 Households and Housing: Choice and Outcomes in the Housing Market CUPR Press, New Brunswick, NJ

Clark W A V and Huang Y 2003 The life course and residential mobility in British housing markets Environment and Planning A 35323 - 339

Clark W A V and Ledwith V 2006 Mobility, housing stress, and neighborhood contexts: Evidence from Los Angeles Environment and Planning A38 1077-1093

Clark W A V Malmberg B and Östh J 2012 Where Does the Mixed Race Population Live: Evidence from Los Angeles? Paper for 2012 Association of American Geographers Annual Meeting in New York

Coulter R and van Ham M 2011 Contextualised mobility histories of moving desires and actual moving behaviour IZA Discussion Paper 6146

Crowder K and South S J 2005 Race, class, and changing patterns of migration between poor and nonpoorneighborhoods, American Journal of Sociology 110 1715-1763

D'Addio A C 2007 Intergenerational Transmission of Disadvantage: Mobility or Immobility Across Generations OECD Social, Employment and Migration Working Papers No. 52 OECD Publishing.

Dearden L Machin S and Reed H 1997 Intergenerational Mobility in Britain Economic Journal 107 47-66

Dietz R D 2002 The estimation of neighborhood effects in the social sciences: an interdisciplinary approach Social Science Research 31 539-575

Dorling D 2010 Injustice: Why Social Inequality PersistsThe Policy Press, Bristol

Duncan G J and Raudenbush S W 2001 Neighborhoods and adolescent development: how can we determine the links? in Booth A and Crouter A C edsDoes it Take a Village? Community Effects on Children, Adolescents, and Families, 105-136 Mahwah, NJ, Lawrence Erlbaum

Durlauf S N 2004 Neighbourhood Effects in Henderson J V and Thisse J F eds Handbook of regional and urban economics Volume 4 Cities and Geography Amsterdam, Elsevier 
Dykstra P and van Wissen L 1999 Introduction: The life course approach as an interdisciplinary framework for population studies in van Wissen $\mathrm{L}$ and Dykstra $\mathrm{P}$ edsPopulation Issues: An Interdisciplinary Focus Plenum Press, New York 1-22

Ellen I G and Turner M A 1997 Does neighbourhood matter? As-sessing recent evidence Housing Policy Debate 8(4) 833-866

Feijten P 2005 Life events and the housing career: A retrospective analysis of timed effectsEburon Publishers

Feijten P and Mulder C H 2005 Life course experience and housing quality Housing Studies 20(4) 571-588

Feijten P Hooimeijer P and Mulder C H 2008 Residential Experience and Residential Environment Choice over the Life-course Urban Studies45(1) 141-162

Galster G and Killen S 1995 The geography of metropolitan opportunity: a reconnaissance and conceptual framework Housing Policy Debate 6 7-43.

Galster G 2002 An economic efficiency analysis of deconcentrating poverty populations Journal of Housing Economics 11(4) 303-329

Geist C and McManus P A 2008 Geographical mobility over the life course: Motivations and implications Population, Space and Place14 283-303

Helderman A and Mulder C H 2007 Intergenerational Transmission of Homeownership: The Roles of Gifts and Continuities in Housing Market Characteristics Urban Studies 44(2) 231-247

Henretta J C 1984 Parental Status and Child's Home Ownership American Sociological Review 49 131-140

Jencks C and Mayer S E 1990 The social consequences of growing up in a poor neighborhood in Lynn L E and McGeary M G H eds Inner-City Poverty in the United States 111-186 Washington DC, National Academy Press

Kasarda J D 1988 Jobs, migration, and emerging urban mismatches in McGeary M G H and Lynn L E (Eds) Urban Change and Poverty 148-198 Washington DC National Academy Press

Kim T K Horner M W and Marans R W 2005 Life cycle and environmental factors in selecting residential and job locations Housing Studies20 457 - 473

Kuntz J Page M E and Solon G 2003 Are point-in-time measures of neighborhood characteristics useful proxies for children's long-run neighborhood environment? Economic Letters 79 231-237

Kurz K 2004 Labour market position, intergenerational transfers and home-ownership. A longitudinal analysis for West German birth cohorts European Sociological Review 20 141-159

Manley D J \& van Ham M 2012 Neighbourhood Effects, Housing Tenure, and Individual Employment Outcomes. in van Ham, M., Manley, D., Bailey, N., Simpson, L., \& Maclennan, D (Eds.), Neighbourhood Effects Research: New Perspectives, Springer Verlag 147-174

Massey D S Gross A B and Shibuya K 1994 Migration, segregation, and the concentration of poverty American Sociological Review 59 425-445

Meen G Meen J \& Nygaard C 2007 A Tale of Two Victorian Cities in the 21st Century. ICHUE - Discussion papers No.007

Menard S 2002 Applied logistic regression analysis London, Sage Publications Inc.

Mulder C H and Hooimeijer P 1999 Residential relocations in the life course in van Wissen L and Dykstra P eds Population Issues: An Interdisciplinary Focus Plenum Press, New York 159-186

Mulder C H and Smits J 1998 First-Time Home-Ownership of Couples The Effect of InterGenerational Transmission European Sociological Review 15 323-337 
Organization for Economic Co-operation and Development (OECD) 2010. Economic Policy Reforms 2010: Going for Growth. OECD Publishing.

Östh J Malmberg B and Andersson E, forthcoming, Analysing segregation using individualized neighbourhoods in Lloyd C D, Shuttleworth I and Wong D eds Social-Spatial Segregation: Concepts, Processes and Outcomes Policy Press

Pollock G 2007 Holistic trajectories: A study of combined employment, housing and family careers by using multiple-sequence analysis Journal of the Royal Statistical Society: Series A170 167-183

Quillian L 2003 How long are exposures to poor neighborhoods? The long-term dynamics of entry and exit from poor neighbourhoods Population Research and Policy Review 22 221-249

Rabe B and Taylor M 2010 Residential mobility, quality of neighbourhood and life course events Journal of the Royal Statistical Society: Series A173(3) 531-555

Rossi P H 1955 Why families move. A study in the social psychology of urban residential mobility Glencoe, Illinois, Free Press

Sampson R J and Wilson W J 1995 Toward a theory of race, crime, and urban inequality in Hagan J and Peterson R D eds Crime and Inequality Stanford, CA, Stanford University Press

Simpson L and Finney N 2009 Spatial patterns of internal migration: evidence for ethnic groups in Britain Population, Space and Place 15 37-56

Solon G 1999 Intergenerational Mobility in the Labor Market in Handbook of Labor Economics, Volume 3 eds Ashenfelter O and Card D 1761-1800

South S J and Crowder K D 1997 Escaping distressed neighborhoods: individual, community, and metropolitan influences American Journal of Sociology, 102, 10401084

South S J and Deane G D 1993 Race and residential mobility: individual determinants and structural constraints, Social Forces 72 147-167

Stovel K and Bolan M 2004 Residential trajectories: using optimal alignment to reveal the structure of residential mobility Sociological Methods \& Research 32 559-598

van Ham M and Manley D 2009 Social Housing Allocation, Choice and Neighbourhood Ethnic Mix in England Journal of Housing and the Built Environment 24 407-422

van Ham M and Manley D 2010 The effect of neighbourhood housing tenure mix on labour market outcomes: a longitudinal investigation of neighbourhood effects Journal of Economic Geography 10(2) 257-282

van Ham M Manley D Bailey N Simpson L and Maclennan D 2012 eds Understanding neighbourhood dynamics: new insights for neighbourhood effects research Springer, Dordrecht

van Ham M Manley D Bailey N Simpson L and Maclennan D 2012 eds Neighbourhood Effects Research: New Perspectives Springer, Dordrecht

van Ham M 2012 Housing Behaviour in Clapham D Clark W A V and Gibb K eds Handbook of Housing Studies Chapter 3 Sage, London

Vartanian T P Buck P W and Gleason P 2007 Intergenerational Neighborhood-Type Mobility: Examining Differences between Blacks and Whites Housing Studies 22 833856 
Table I Descriptives of neighbourhood quintiles (1990 and 2008)

\begin{tabular}{|c|c|c|c|c|c|c|c|c|c|c|c|c|}
\hline \multirow[b]{3}{*}{$\begin{array}{l}\text { Neighbourhood } \\
\text { quintiles }\end{array}$} & \multicolumn{6}{|c|}{1990} & \multicolumn{6}{|c|}{2008} \\
\hline & \multicolumn{2}{|c|}{$\begin{array}{l}\text { \% low income } \\
\text { neighbours }\end{array}$} & \multicolumn{2}{|c|}{$\begin{array}{l}\text { \% ethnic } \\
\text { minorities }\end{array}$} & \multicolumn{2}{|c|}{ \% public rentals } & \multicolumn{2}{|c|}{$\begin{array}{l}\text { \% low income } \\
\text { neighbours }\end{array}$} & \multicolumn{2}{|c|}{$\begin{array}{l}\text { \% ethnic } \\
\text { minorities }\end{array}$} & \multicolumn{2}{|c|}{ \% public rentals } \\
\hline & Mean & $\begin{array}{l}\text { Std } \\
\text { Dev. }\end{array}$ & Mean & $\begin{array}{l}\text { Std } \\
\text { Dev. }\end{array}$ & Mean & $\begin{array}{l}\text { Std } \\
\text { Dev. }\end{array}$ & Mean & $\begin{array}{l}\text { Std } \\
\text { Dev. }\end{array}$ & Mean & $\begin{array}{l}\text { Std } \\
\text { Dev. }\end{array}$ & Mean & $\begin{array}{l}\text { Std } \\
\text { Dev. }\end{array}$ \\
\hline 1 (low poverty) & 0.101 & 0.015 & 0.022 & 0.020 & 0.067 & 0.170 & 0.096 & 0.014 & 0.064 & 0.053 & 0.046 & 0.137 \\
\hline 2 & 0.132 & 0.007 & 0.038 & 0.036 & 0.202 & 0.283 & 0.123 & 0.006 & 0.072 & 0.061 & 0.089 & 0.194 \\
\hline 3 & 0.155 & 0.007 & 0.052 & 0.046 & 0.343 & 0.356 & 0.145 & 0.007 & 0.083 & 0.069 & 0.119 & 0.228 \\
\hline 4 & 0.181 & 0.009 & 0.072 & 0.059 & 0.483 & 0.399 & 0.174 & 0.011 & 0.097 & 0.081 & 0.149 & 0.259 \\
\hline $\begin{array}{l}5 \text { (poverty } \\
\text { concentration) }\end{array}$ & 0.241 & 0.054 & 0.189 & 0.153 & 0.615 & 0.397 & 0.248 & 0.062 & 0.163 & 0.151 & 0.264 & 0.360 \\
\hline
\end{tabular}


Table II Descriptive statistics of research population in 1990 (when living with parents), 1995, 2002 and 2008.Values in percentages unless otherwise stated. Due to missing data on some individuals/years, values do not always sum up to $100 \%$.

\begin{tabular}{|c|c|c|c|c|}
\hline & 1990 & 1995 & 2002 & 2008 \\
\hline Share males & 48.7 & 48.7 & 48.7 & 48.7 \\
\hline Age Mean (Std dev.) & $21.04(2.18)$ & $26.04(2.18)$ & $33.04(2.18)$ & $39.04(2.18)$ \\
\hline Share ethnic minorities ${ }^{1}$ & 3.2 & 3.2 & 3.2 & 3.2 \\
\hline \multicolumn{5}{|l|}{ Neighbourhood quintile } \\
\hline 1 & 24.7 & 7.9 & 17.1 & 21.2 \\
\hline 2 & 17.9 & 8.9 & 14.6 & 17.0 \\
\hline 3 & 15.0 & 14.6 & 15.5 & 18.4 \\
\hline 4 & 16.2 & 23.2 & 22.7 & 19.5 \\
\hline 5 & 26.2 & 45.5 & 30.1 & 24.0 \\
\hline Share with children & 7.4 & 31.5 & 63.3 & 75.4 \\
\hline Share couples (ref = singles) & 8.2 & 32.1 & 59.0 & 66.7 \\
\hline Share students & 32.7 & 14.8 & 6.5 & 2.5 \\
\hline \multicolumn{5}{|l|}{ Level of education } \\
\hline low & 60.3 & 53.1 & 45.4 & 42.6 \\
\hline medium & 38.1 & 40.5 & 37.6 & 36.7 \\
\hline high & 1.6 & 6.5 & 17.0 & 20.7 \\
\hline Share employed ${ }^{2}$ & - & 79.5 & 89.4 & 92.1 \\
\hline $\begin{array}{l}\text { Income from work (10,000 } \\
\text { SEK) Mean (Std dev.) }\end{array}$ & $8.89(5.32)$ & $13.91(8.13)$ & $24.93(17.39)$ & $33.94(29.24)$ \\
\hline Share receiving social benefits & 5.9 & 6.6 & 1.5 & 1.4 \\
\hline \multicolumn{5}{|l|}{ Housing tenure } \\
\hline home ownership & 50,4 & 12.0 & 35.8 & 50.4 \\
\hline cooperative & 11.5 & 33.0 & 22.4 & 21.7 \\
\hline private rental & 9.2 & 25.6 & 16.7 & 10.5 \\
\hline public rental & 19.5 & 23.8 & 13.4 & 10.3 \\
\hline $\mathrm{N}$ & 13,530 & 13,530 & 13,530 & 13,530 \\
\hline
\end{tabular}

${ }^{1}$ By ethnic minorities, we refer to people born in non-western countries.

${ }^{2}$ Due to a change in measurement of employment status between 1992 and 1993, we do not report figures for 1990.

Table IIICumulative exposure to neighbourhood income quintiles 1991-2008 (years of exposure as percentage of total years )

\begin{tabular}{lllllll}
\hline & \multicolumn{7}{c}{ Cumulative exposure to neighbourhood income quintiles 1991-2008 } \\
\hline $\begin{array}{l}\text { Parental neighbourhood } \\
\text { in 1990 (quintiles) }\end{array}$ & 1 & 2 & 3 & 4 & 5 & Total \\
\hline $\begin{array}{l}\text { 1 Low poverty } \\
\text { neighbourhood }\end{array}$ & 17.9 & 14.9 & 16.0 & 20.6 & 30.6 & 100 \\
2 & 16.3 & 14.7 & 16.9 & 21.9 & 30.3 & 100 \\
3 & 13.1 & 12.8 & 16.9 & 23.6 & 33.6 & 100 \\
4 & 10.6 & 10.9 & 15.7 & 24.4 & 38.3 & 100 \\
5 Poverty concentration & & & & & & \\
neighbourhood & 8.9 & 9.0 & 13.1 & 20.3 & 48.8 & 100 \\
\hline
\end{tabular}

Source: Authors calculations on GeoSweden dataset 
Figure 1 Neighbourhood histories 1990-2008 (10\% sample of histories) of those leaving the parental home 1990-1991 by parental neighbourhood quintile (1, 3 and 5).

Fig 1.1 Parental neighbourhood quintile 1 in 1990 (low poverty neighbourhood)

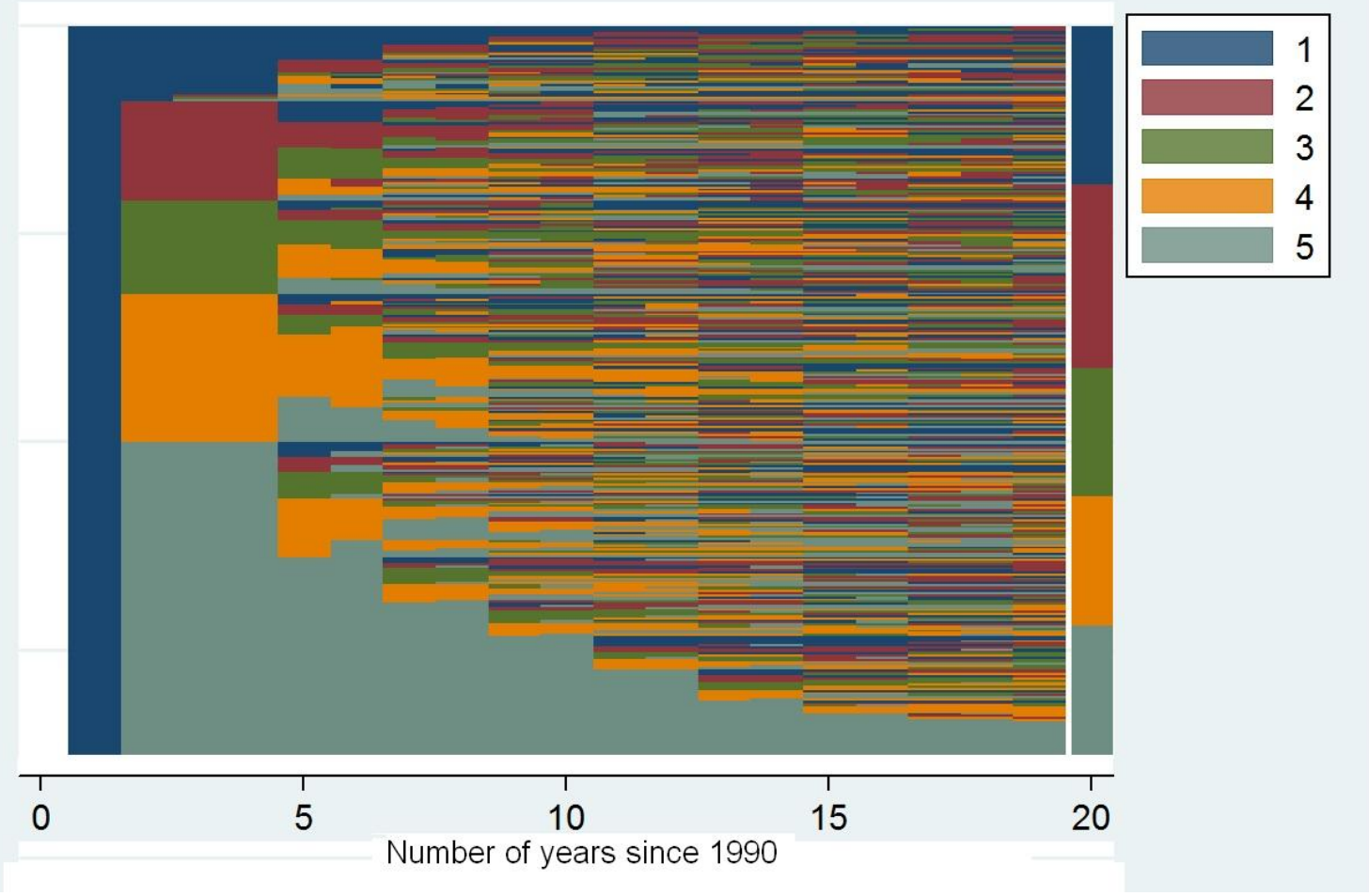

Fig 1.2 Parental neighbourhood quintile 3 in 1990

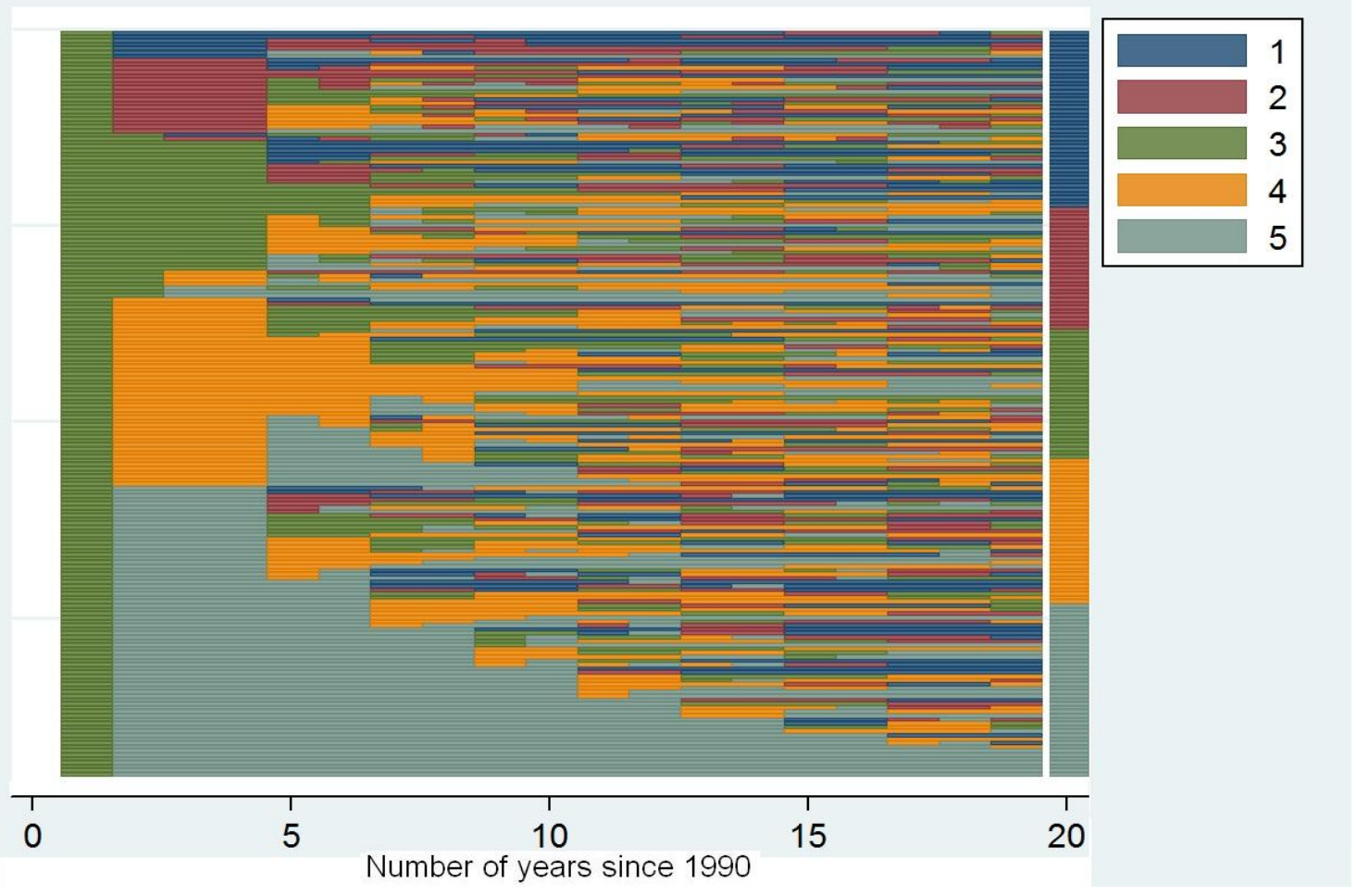


Fig 1.3 Parental neighbourhood quintile 5 in 1990 (poverty concentration neighbourhood)

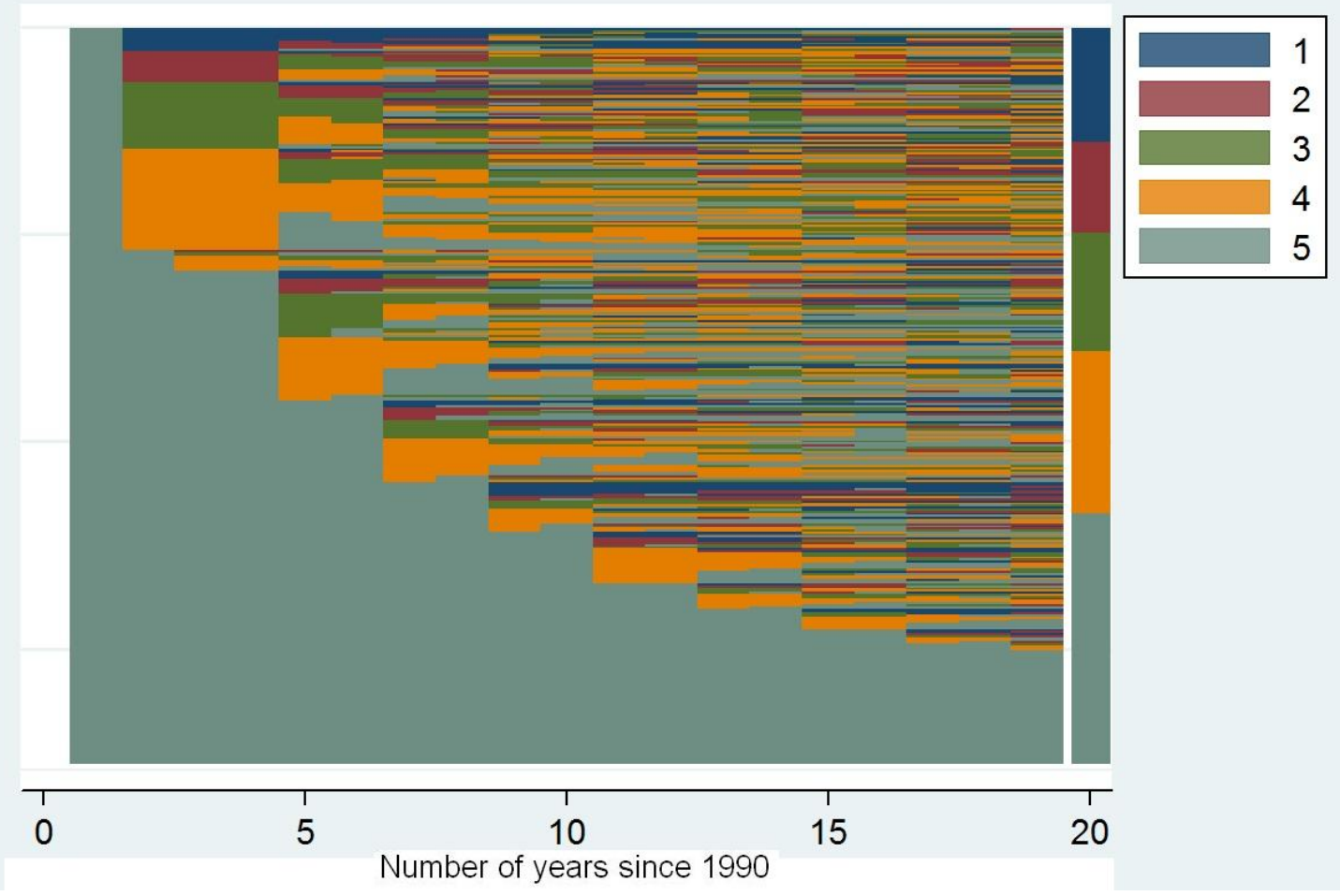

Fig 2 Neighbourhood histories 1990-2008, ethnic minorities (no sample but full population) with parental neighbourhood quintile 5 in 1990

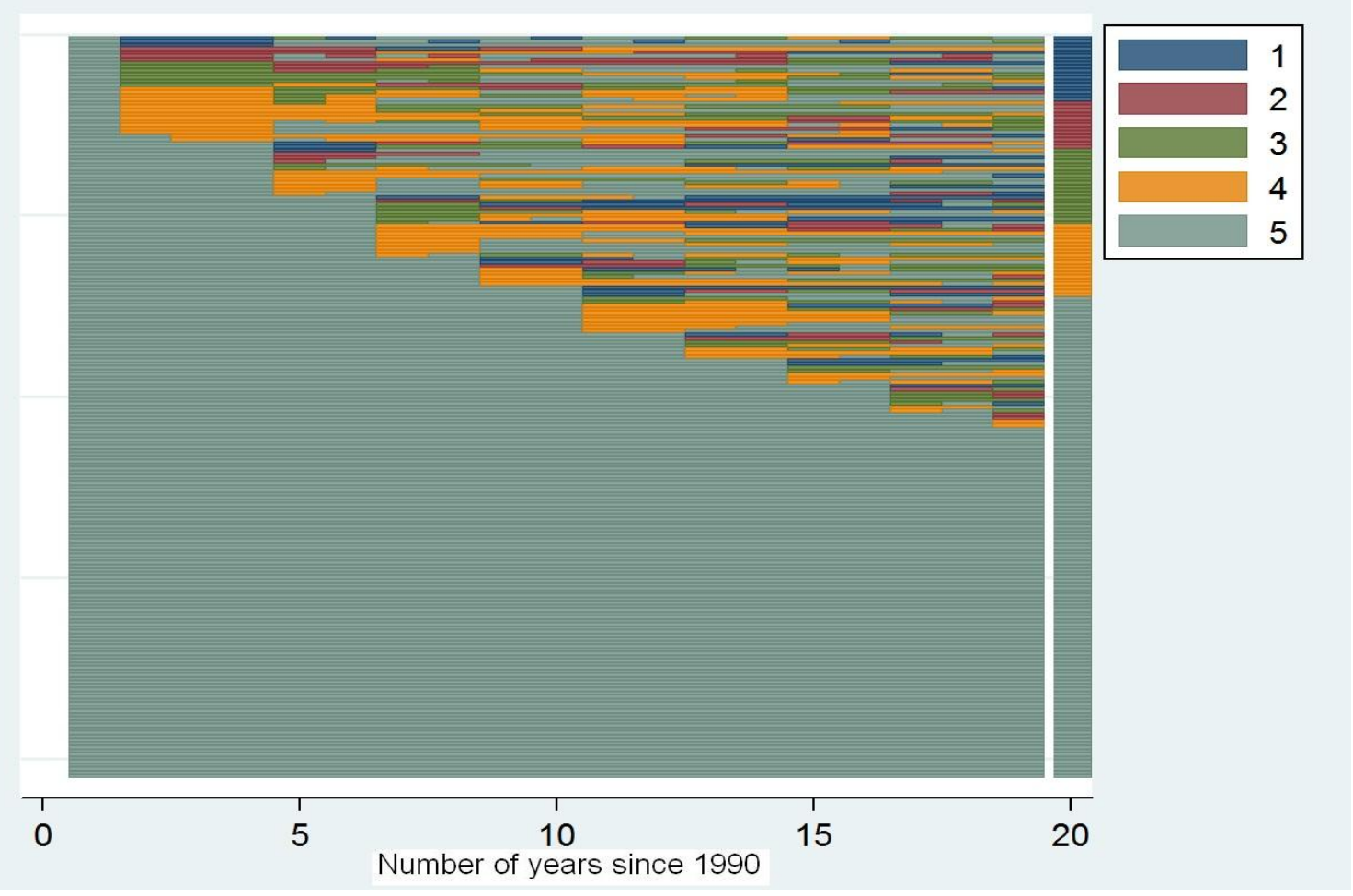


Fig 3 Stable neighbourhood histories 1990-2008 with same neighbourhood in 2008 as parental neighbourhood in 1990 (25\% sample)

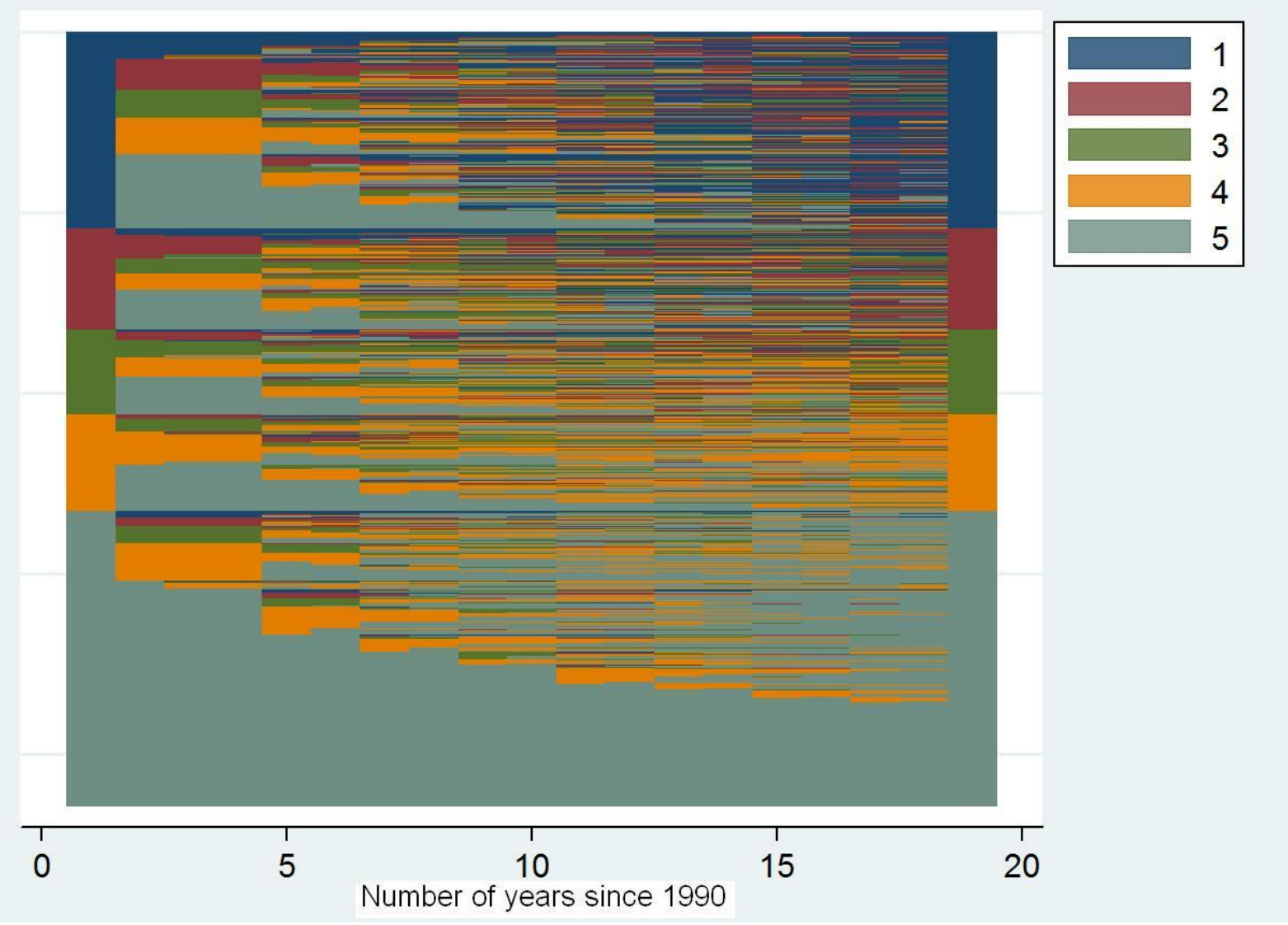


Table IV Ordered Logit models of neighbourhood quintile (1-5) 5, 12 and 18 years after leaving the parental home

\begin{tabular}{|c|c|c|c|c|c|c|c|c|c|c|c|c|}
\hline & \multicolumn{4}{|c|}{ After 5 years $^{1}$} & \multicolumn{4}{|c|}{ After 12 years } & \multicolumn{4}{|c|}{ After 18 years } \\
\hline & Coeff. & Std Err & Coeff. & Std Err & Coeff. & Std Err & Coeff. & Std Err & Coeff. & Std Err & Coeff. & Std Err \\
\hline Parent NBH Q1 & Ref & Ref & Ref & Ref & Ref & Ref & Ref & Ref & Ref & Ref & Ref & Ref \\
\hline Parent NBH Q2 & -0.004 & 0.052 & -0.002 & 0.053 & 0.083 & 0.050 & 0.080 & 0.052 & $0.106^{*}$ & 0.049 & $0.125^{*}$ & 0.051 \\
\hline Parent NBH Q3 & $0.117^{*}$ & 0.055 & $0.113^{*}$ & 0.057 & $0.249 * * *$ & 0.053 & $0.244 * * *$ & 0.055 & $0.189 * * *$ & 0.052 & $0.197 * * *$ & 0.054 \\
\hline Parent NBH Q4 & $0.267 * * *$ & 0.054 & $0.249 * * *$ & 0.056 & $0.438 * * *$ & 0.053 & $0.440 * * *$ & 0.055 & $0.349 * * *$ & 0.052 & $0.340 * * *$ & 0.054 \\
\hline Parent NBH Q5 & $0.395 * * *$ & 0.049 & $0.405^{* * *}$ & 0.052 & $0.506 * * *$ & 0.048 & $0.523 * * *$ & 0.050 & $0.363 * * *$ & 0.047 & $0.387 * * *$ & 0.049 \\
\hline Non-western immigrant & 0.501 & 0.317 & $1.646 *$ & 0.724 & -0.401 & 0.297 & 0.249 & 0.590 & -0.078 & 0.296 & 0.488 & 0.593 \\
\hline Parent NBH Q1*ethnic minority & Ref & Ref & Ref & Ref & Ref & Ref & Ref & Ref & Ref & Ref & Ref & Ref \\
\hline Parent NBH Q2*ethnic minority & $-1.017^{*}$ & 0.431 & $-2.235^{* *}$ & 0.848 & 0.418 & 0.425 & 0.474 & 0.768 & -0.123 & 0.405 & -0.723 & 0.734 \\
\hline Parent NBH Q3*ethnic minority & 0.040 & 0.472 & -0.394 & 1.006 & $1.311^{* *}$ & 0.456 & 0.657 & 0.834 & 0.625 & 0.436 & 0.062 & 0.831 \\
\hline Parent NBH Q4*ethnic minority & -0.374 & 0.434 & -0.998 & 0.980 & $1.010^{*}$ & 0.417 & 0.805 & 0.826 & 0.319 & 0.398 & 0.230 & 0.802 \\
\hline Parent NBH Q5*ethnic minority & 0.333 & 0.359 & -0.445 & 0.765 & $1.196 * * *$ & 0.333 & 0.819 & 0.623 & $1.080 * *$ & 0.332 & 0.697 & 0.626 \\
\hline Female & -0.034 & 0.036 & -0.039 & 0.038 & 0.042 & 0.036 & 0.054 & 0.038 & 0.013 & 0.035 & 0.038 & 0.037 \\
\hline Children & 0.061 & 0.063 & 0.062 & 0.066 & -0.075 & 0.054 & -0.090 & 0.057 & 0.090 & 0.054 & 0.057 & 0.057 \\
\hline Couple & $-0.164 * *$ & 0.061 & $-0.176 * *$ & 0.064 & $-0.106^{*}$ & 0.054 & -0.098 & 0.057 & $-0.173^{* *}$ & 0.050 & $-0.181^{* *}$ & 0.053 \\
\hline Low education & Ref & Ref & Ref & Ref & Ref & Ref & Ref & Ref & Ref & Ref & Ref & Ref \\
\hline Middle education & $-0.116 * *$ & 0.037 & $-0.120 * *$ & 0.040 & -0.024 & 0.037 & -0.045 & 0.040 & $-0.169 * * *$ & 0.037 & $-0.175^{* * *}$ & 0.039 \\
\hline University degree & -0.064 & 0.070 & -0.070 & 0.075 & $0.105^{*}$ & 0.048 & 0.073 & 0.052 & $-0.207 * * *$ & 0.045 & $-0.210 * * *$ & 0.048 \\
\hline Student & -0.038 & 0.056 & -0.026 & 0.060 & 0.006 & 0.071 & -0.009 & 0.076 & -0.016 & 0.103 & -0.026 & 0.111 \\
\hline Income from work $(10,000$ SEK) & $-0.014 * * *$ & 0.003 & $-0.014 * * *$ & 0.003 & -0.001 & 0.001 & -0.001 & 0.001 & $-0.003 * * *$ & 0.001 & $-0.002 * *$ & 0.001 \\
\hline Social benefits & 0.116 & 0.081 & 0.092 & 0.087 & $0.411^{*}$ & 0.159 & 0.299 & 0.173 & $0.619 * * *$ & 0.169 & $0.541 * *$ & 0.181 \\
\hline Home ownership & Ref & Ref & Ref & Ref & Ref & Ref & Ref & Ref & Ref & Ref & Ref & Ref \\
\hline Coop housing & $1.072^{* * *}$ & 0.056 & $1.068 * * *$ & 0.059 & $1.473 * * *$ & 0.045 & $1.455^{* * *}$ & 0.048 & $1.158 * * *$ & 0.043 & $1.130 * * *$ & 0.045 \\
\hline Private renting & $1.573 * * *$ & 0.060 & $1.557 * * *$ & 0.063 & $2.154 * * *$ & 0.052 & $2.168 * * *$ & 0.055 & $1.785^{* * *}$ & 0.057 & $1.744 * * *$ & 0.061 \\
\hline Public renting & $2.607^{* * *}$ & 0.065 & $2.549 * * *$ & 0.068 & $2.898 * * *$ & 0.061 & $2.889 * * *$ & 0.065 & $2.921^{* * *}$ & 0.067 & $2.913^{* * *}$ & 0.072 \\
\hline Parent income from work $(10,000$ SEK) & & & 0.000 & 0.001 & & & $0.004 *$ & 0.001 & & & 0.001 & 0.001 \\
\hline /cut1 & -1.458 & 0.083 & -1.489 & 0.091 & -0.628 & 0.065 & -0.553 & 0.074 & -0.821 & 0.063 & -0.792 & 0.071 \\
\hline /cut2 & -0.516 & 0.081 & -0.550 & 0.089 & 0.379 & 0.065 & 0.463 & 0.074 & 0.140 & 0.063 & 0.161 & 0.071 \\
\hline /cut3 & 0.420 & 0.081 & 0.389 & 0.089 & 1.256 & 0.066 & 1.337 & 0.075 & 1.0842 & 0.064 & 1.107 & 0.072 \\
\hline /cut4 & 1.578 & 0.082 & 1.550 & 0.090 & 2.541 & 0.069 & 2.629 & 0.078 & 2.235 & 0.066 & 2.266 & 0.074 \\
\hline Initial LL & -17692 & & -15932 & & -19928 & & -17928 & & -20845 & & -18708 & \\
\hline Final LL & -16392 & & -14803 & & -17563 & & -15833 & & -18826 & & -16959 & \\
\hline Number of obs ${ }^{2}$ & 12,743 & & 11,421 & & 12,686 & & 11,373 & & 13,004 & & 11,663 & \\
\hline Prob > chi2 & 0.0000 & & 0.0000 & & 0.0000 & & 0.0000 & & 0.0000 & & 0.0000 & \\
\hline Pseudo R2 & 0.0735 & & 0.0709 & & 0.1187 & & 0.1168 & & 0.0968 & & 0.0935 & \\
\hline
\end{tabular}

${ }^{1}$ We use 5 instead of 6 years here due to the reliability of the housing data available in year 6.

${ }^{2}$ The differences in the number of observations between models are due to small amounts of missing data.

$*=\mathrm{p}<0.10 ; * *=\mathrm{p}<0.05 ; * * *=\mathrm{p}<0.01$ 
Table $\mathbf{V}$ Linear regression of years of exposure (min 0 and max 18 years) to poverty concentration (quintile 5) neighbourhoods after leaving the parental home

\begin{tabular}{|c|c|c|c|}
\hline & Coeff. & Std. Err. & \\
\hline Parent NBH Q1 & Ref & Ref & \\
\hline Parent NBH Q2 & -0.086 & 0.130 & \\
\hline Parent NBH Q3 & 0.279 & 0.139 & $* *$ \\
\hline Parent NBH Q4 & 0.683 & 0.136 & $* * *$ \\
\hline Parent NBH Q5 & 1.586 & 0.124 & $* * *$ \\
\hline Non-western immigrant & 3.395 & 1.412 & $* * *$ \\
\hline Parent NBH Q1*ethnic minority & Ref & Ref & \\
\hline Parent NBH Q2*ethnic minority & -2.610 & 1.794 & \\
\hline Parent NBH Q3*ethnic minority & -0.586 & 1.920 & \\
\hline Parent NBH Q4*ethnic minority & -0.084 & 1.836 & \\
\hline Parent NBH Q5*ethnic minority & -0.100 & 1.463 & \\
\hline Female & -0.129 & 0.095 & \\
\hline Number of years with children $(0-18)$ & 0.006 & 0.009 & \\
\hline Number of years in couple (0-18) & -0.008 & 0.010 & \\
\hline Low education & Ref & Ref & \\
\hline Middle education & -0.272 & 0.104 & $* * *$ \\
\hline University degree & -0.243 & 0.163 & \\
\hline Number of years studying (0-18) & -0.011 & 0.025 & \\
\hline Mean income from work $(10,000$ SEK) & -0.046 & 0.006 & $* * *$ \\
\hline Work income range & 0.010 & 0.002 & $* * *$ \\
\hline Number of years on social benefits (0-18) & 0.134 & 0.025 & $* * *$ \\
\hline Number of years in public rental $(0-18)$ & 0.316 & 0.009 & $* * *$ \\
\hline Number of years in home ownership (0-18) & -0.207 & 0.009 & $* * *$ \\
\hline Parent income from work $(10,000$ SEK) & 0.003 & 0.004 & \\
\hline Constant & 7.019 & 0.202 & $* * *$ \\
\hline Number of obervations ${ }^{1}$ & 12,105 & & \\
\hline $\mathrm{F}$ & 230.59 & & \\
\hline Adjusted R2 & 0.2849 & & \\
\hline
\end{tabular}

${ }^{1}$ The number of observations $<$ total sample due to missing data.

$*=p<0.10 ;{ }^{* *}=p<0.05 ;{ }^{* * *}=p<0.01$ 